\title{
Identification and integrative analysis of microRNAs and mRNAs involved in proliferation and invasion of pressure-treated human liver cancer cell lines
}

\author{
SI SHEN, XU LUO, KEWEI GAO, YUNCHEN SUN, DINGKANG YAO and LIANG ZHU
}

Department of Gastroenterology, Changzheng Hospital, Second Military Medical University, Shanghai 200003, P.R. China

Received October 21, 2018; Accepted April 30, 2019

DOI: $10.3892 / \mathrm{mmr} .2019 .10223$

\begin{abstract}
Mechanical pressure may contribute to the development of cancer; however, there is currently no evidence regarding the effect of mechanical pressure on liver cancer. In the present study, 2- and 3-dimensional pressure-loading systems were used to exert pressure on HepG2 and Huh-7 cell lines. Cell proliferation and flow cytometry analyses were undertaken to observe the proliferative ability of pressure-loaded cells. In addition, Transwell, wound-healing and reverse transcription-quantitative polymerase chain reaction (RT-qPCR) assays were applied to evaluate the migratory and invasive ability of pressurized cells. Analyses of microRNA (miRNA) and mRNA expression profiles were performed to screen for differentially expressed miRNAs and mRNAs, which were validated by RT-qPCR. Bioinformatics analyses were subsequently performed to investigate the putative target genes and associated pathways. The proliferation and invasion of HepG2 and Huh-7 cell lines were significantly
\end{abstract}

Correspondence to: Dr Liang Zhu or Dr Dingkang Yao, Department of Gastroenterology, Changzheng Hospital, Second Military Medical University, 415 Fengyang Road, Huangpu, Shanghai 200003, P.R. China

E-mail: czzhuliang@smmu.edu.cn

E-mail: czyaodingkang@163.com

Abbreviations: 2D, 2-dimensional; 3D, 3-dimensional; RT-qPCR, reverse transcription-quantitative polymerase chain reaction; PI3K, phosphoinositide 3-kinase; FOXO, forkhead box O; ECM, extracellular matrix; CAFs, cancer-associated fibroblasts; HSCs, hepatic stellate cells; miRNA, microRNA; GO, Gene Ontology; DMEM, Dulbecco's modified Eagle's medium; CCK-8, Cell Counting kit-8; MMPs, matrix metalloproteinase; TIMPs, tissue inhibitor of metalloproteinase; Src, SRC proto-oncogene, non-receptor tyrosine kinase; Akt, protein kinase B; ITGAV, integrin subunit $\alpha \mathrm{V} ; \mathrm{p}$, phosphorylated; SGKs, serum/glucocorticoid regulated kinases; SOS1, son of sevenless 1; IRS1, insulin receptor substrate 1; EMT, epithelial-mesenchymal transition; CSNK1E, casein kinase $1 \varepsilon$; SMAD2, SMAD family member 2; CAMs, cell adhesion molecules

Key words: pressure, mechanotransduction, cell proliferation, invasion, liver cancer increased under a pressure of $15 \mathrm{mmHg}$ for $24 \mathrm{~h}$. Under this condition, five differentially expressed miRNAs (fold change $\geq 1.2, \mathrm{P} \leq 0.05$ ) and 10,150 differentially expressed mRNAs (fold change $\geq 2, \mathrm{P} \leq 0.05$ ) were identified. A total of 1,309 genes were identified from the integrative analysis of miRNAs and mRNAs. In addition, the bioinformatics analyses revealed that the majority of these miRNAs and mRNAs were associated with several pathways associated with cell proliferation and invasion, including 'PI3K/Akt signaling pathway', 'focal adhesion', 'integrin-mediated signaling pathway', 'FOXO signaling pathway' and 'Hippo signaling pathway'. The present study described the pressure-dependent proliferation and invasion of liver cancer cells, and revealed the potential molecular mechanisms underlying them. The identification of miRNAs and their putative targets may also result in novel treatment strategies for liver cancer.

\section{Introduction}

Liver cancer is currently the second leading cause of cancer-associated mortality worldwide, with the highest incidence being reported in Asia and sub-Saharan Africa (1). However, the pathophysiology of mechanical pressure in liver cancer development has not been definitively elucidated.

During the development of liver cancer, cancerous cells may be subjected to various forms of mechanical pressures, including pressure from the extracellular matrix (ECM) caused by matrix stiffness (2); the mechanical-pressure effect caused by rapid tumor growth (3); portal hypertension, caused when the portal pressure gradient or the pressure difference between the portal and inferior cava vein strongly increases (4); pressure generated by the blood and lymphatic transport of shed cancer cells (5); or pressure from iatrogenic intraoperative stimulation $(4,5)$. During recent decades, studies have provided evidence that pressure serves a distinctive role in malignant cell proliferation and invasion: Craig et al (5) reported that activation of cancer cells by pressure promotes tumor development and impaired tumor-free survival. Furthermore, Basson et al (6) revealed that increased extracellular pressure activates a mechanosensitive calcium pathway to further enhance the proliferation of tumor cells, and Fiering et al (7) demonstrated that the mechanical pressure from cancer-associated fibroblasts (CAFs) leads to the progression of metastasis. Fernández-Sánchez et al (8) explored the 
contribution of mechanical pressure exerted by tumor growth onto non-tumorous adjacent epithelium, and demonstrated that that the tumorigenic $\beta$-catenin pathway could be mechanically activated in healthy epithelial cells surrounding the tumor, suggesting an unexplored mode of tumor propagation based on mechanical signaling pathways.

MicroRNAs (miRNAs/miRs) are small non-coding RNAs considered to be key post-transcriptional modulators of gene expression, which target mRNA for translational repression or destabilization (9). Mechanically responsive miRNAs are sensitive or responsive to mechanotransduction. To date, some mechanically induced miRNAs have been associated with physiological or pathological processes (10-13). The preliminary results of a previous study confirmed that the mechanically responsive miR-9a-5p regulates proliferation and migration of hepatic stellate cells (HSCs) through inhibition of sirtuin 1 (Sirt1) (13). Clinical data has revealed that $90 \%$ of patients with liver cancer have a background of liver cirrhosis (14), and the median overall survival rate of patients with liver cancer and a liver cirrhosis background has significantly decreased (15). Currently, elevated portal pressure has been exclusively considered a consequence of liver cirrhosis (16), but whether mechanosensitive miRNAs have a pivotal role in the subsequent development of liver cancer remains unknown. In addition, it may be hypothesized that the increased recurrence rate following hepatectomy is associated with the increased biological activity of liver cancer cells following intraoperative mechanical stimulation. However, the role of miRNAs in this process should be further evaluated.

To investigate alterations in the proliferation and invasion of liver cancer cell lines following mechanical stimulation, HepG2 and Huh-7 cell lines were subjected to gradually increasing pressure $(0,5,15,30$ and $60 \mathrm{mmHg})$ for different periods of time $(0,12,24$ and $48 \mathrm{~h})$ using 2-dimensional (2D) and 3-dimensional (3D) pressure-loading systems. Subsequently, the differentially expressed miRNAs and mRNAs were screened under optimal conditions $(15 \mathrm{mmHg}$, $24 \mathrm{~h}$ ) by microarray analysis. The target genes of miRNAs and the differentially expressed mRNAs were integrated, and 1,309 genes were bioinformatically predicted to respond to mechanical pressure. Through Gene Ontology (GO) and pathway analyses, it was revealed that the function of these target genes was primarily associated with proliferation and invasion.

\section{Materials and methods}

Cell culture and reagents. The HepG2 cell line was purchased from American Type Culture Collection (cat. no. HB-8065). The Huh-7 cell line was purchased from the Japanese Collection of Research Bioresources Cell Bank (cat. no. 0403). Mycoplasma testing was performed for all cell lines and no infection was found. The cell lines were both authenticated by short tandem repeat analysis. Cells were cultured at $37^{\circ} \mathrm{C}$ in an atmosphere containing $5 \% \mathrm{CO}_{2}$ in Dulbecco's modified Eagle's medium (DMEM; HyClone; GE Healthcare Life Sciences) containing 10\% fetal bovine serum (FBS; Gibco; Thermo Fisher Scientific, Inc.), $2 \mathrm{mM}$ glutamine, $1 \mathrm{mM}$ sodium pyruvate, $10 \mathrm{mM}$ HEPES, $100 \mathrm{U} / \mathrm{ml}$ penicillin $\mathrm{G}$ and $100 \mathrm{mg} / \mathrm{ml}$ streptomycin (Sigma-Aldrich; Merck KGaA). Cells were digested with EDTA- $0.25 \%$ trypsin (Thermo Fisher Scientific, Inc.) during cell passage.

Pressure loading. The 2D and 3D pressure-loading systems were used to exert increasing pressure $(0,5,15,30$ and $60 \mathrm{mmHg})$ for various periods of time $(0,12,24$ and $48 \mathrm{~h})$. The $2 \mathrm{D}$ pressure-loading system used in the present study was designed by previous studies (17-19). The container was made from stainless steel, the cap of which contained an input port and an output port that can be opened and tightly sealed with a rubber ring. The inlet was connected to high-pressure helium by a silica gel sorbent tube and a pressure regulator, and the outlet was connected to a three-way control valve, of which one end was connected to a buffer gas valve and the other end was connected to a medical sphygmomanometer to read the pressure in the container. When the cells were cultured under pressure, the system was placed in a $5 \% \mathrm{CO}_{2}$ incubator.

Pressure loading of 3D cultured cells was undertaken using a Flexcell-5000 Compression system (Flexcell International Corporation). Prior to pressure loading, the cells were cultured in 3D Life Biomimetic Hydrogels (Cellendes $\mathrm{GmbH}$ ) for $4 \mathrm{~h}$. The cell gels were placed in a BioPres Compression Culture Plate (Flexcell International Corporation), and the pressure parameters, including compressive strength and intervention time, were adjusted digitally using FlexSoft FX-5000 ${ }^{\mathrm{TM}}$ (Flexcell International Corporation). The cells in gel were detached by $1 \mathrm{X}$ Accutase enzymes (Innovative Cell Technologies, Inc.), and centrifuged for $10 \mathrm{~min}$ at $111.8 \mathrm{x} \mathrm{g}$ at room temperature. The cells were subsequently collected for follow-up experiments.

Cell counting kit-8 (CCK-8) assay. Cell proliferation was analyzed using the CCK- 8 assay (Dojindo Molecular Technologies, Inc.). Cells were plated in 96-well plates at $1 \times 10^{4}$ cells/well. At four different time-points $(0,12,24$ and $48 \mathrm{~h}), 10 \mu \mathrm{l}$ CCK-8 solution was added to each well, and the cells were incubated for a further $2 \mathrm{~h}$ at room temperature. The optical density value was obtained by determining the differences in absorbance at a wavelength of $450 \mathrm{~nm}$ using a microplate reader (KHB-ST-360; Shanghai Kehua Bio-engineering Co., Ltd.). The activity of cellular dehydrogenases generates formazan dye, the amount of which is directly proportional to the number of living cancer cells.

Cell cycle analysis. Cell cycle arrest was measured using a Cell Cycle Assay kit (Hangzhou MultiSciences Biotech, Co., Ltd.). A total of $2 \times 10^{5}-1 \times 10^{6} 3 \mathrm{D}$-cultured and pressure-treated cells were collected and centrifuged for $10 \mathrm{~min}$ at $111.8 \mathrm{x} \mathrm{g}$ at room temperature. After the supernatant was discarded, cells were washed once with PBS (HyClone; GE Healthcare Life Sciences). Afterwards, DNA staining solution $(1 \mathrm{ml})$ was added to the cells. The mixture was spun for 5-10 sec, and incubated at room temperature for $30 \mathrm{~min}$. Finally, the mixed solution was collected for analysis via flow cytometry using FlowJo V10 software (FlowJo LLC).

Cell invasion assay. The cell invasion assay was performed using Transwell ${ }^{\circledR}$ Permeable Supports, which consisted of Snapwell $^{\mathrm{TM}}$ and Netwell ${ }^{\mathrm{TM}}$ inserts (Corning Inc.). The kit contained 24 inserts; each insert contained a polycarbonate 
membrane with $8-\mu \mathrm{m}$ pores coated with a thin layer of type I/III collagen-coated polytetrafluoroethylene. Briefly, serum-free DMEM was used to prepare cell suspension, and $200 \mu \mathrm{l}$ cell suspension containing $0.5 \times 10^{4}$ cells was added to the upper chamber of each pore; DMEM containing 10\% FBS was added to each lower chamber as a chemoattractant. The cells were cultured for $24 \mathrm{~h}$. Subsequently, non-migratory cells on the upper surface were scraped off. The migrated cells were fixed with $4 \%$ paraformaldehyde for $30 \mathrm{~min}$ at room temperature and stained with $0.1 \%$ crystal violet for $5 \mathrm{~min}$ at room temperature. Acetic acid (10\%) was used to elute the stained inserts to detect the percentage of invaded cells. Images of the cells were then captured using a light microscope (magnification, $\mathrm{x} 100$ ).

Wound-healing assay. Cells (5x10\%/well) were seeded into 24-well plates (Corning, Inc.); after $24 \mathrm{~h}$, the cells reached $70-80 \%$ confluence as a monolayer. A new pipette tip (100 $\mu \mathrm{l})$ was used to gently scratch the monolayer across the center of the well. After scratching, the well was washed twice with DMEM to remove the detached cells. The well was then replenished with fresh DMEM containing 10\% FBS, and incubated for an additional $24 \mathrm{~h}$ at $37^{\circ} \mathrm{C}$. The cells were subsequently washed twice with PBS, and fixed with $3.7 \%$ paraformaldehyde for $30 \mathrm{~min}$ at room temperature and stained with $1 \%$ crystal violet in $2 \%$ ethanol for $30 \mathrm{~min}$ at room temperature. Images of the cells were captured using a light microscope (magnification, $\mathrm{x} 100)$. The gap distances were measured using ImageJ V1.51 (National Institutes of Health).

Cell mortality assay. The HepG2 and Huh-7 cells in logarithmic growth phase were inoculated in 6-cm culture dishes (Corning, Inc.) at a density of $1 \times 10^{6}$ cells $/ \mathrm{ml} ; 5 \mathrm{ml}$ cell suspension was added to each dish. Cells were cultured in DMEM containing $10 \%$ FBS and pressure-loaded $(0,5,15,30$ and $60 \mathrm{mmHg})$ for a set period of time $(0,12,24$ and $48 \mathrm{~h})$. Cells were then digested with EDTA-0.25\% trypsin (Thermo Fisher Scientific, Inc.) to prepare a $0.2-\mathrm{ml}$ cell suspension. The cells were mixed evenly with $0.3 \mathrm{ml} \mathrm{PBS}$ and $0.5 \mathrm{ml} 0.4 \%$ trypan blue staining solution (Sigma-Aldrich; Merck KGaA) for 5-15 min at room temperature. The total number of cells and the number of cells stained with trypan blue were counted on a hemocytometer. Finally, the cell survival rate was calculated according to the following formula: Cell mortality=(no. of blue-stained cells/total no. of cells)x100.

Microarray analysis of miRNA expression. A total of three samples were allocated to the control and pressure groups. Total RNA was extracted by TRIzol ${ }^{\circledR}$ reagent (Thermo Fisher Scientific, Inc.) according to the manufacturer's protocol and purified using miRNeasy Mini kit (Qiagen GmbH). After the assessment of RNA quality and quantity, microarray analysis of miRNA expression (Agilent Human miRNA V21.0 Array; Agilent Technologies, Inc.) was performed, according to the manufacturer's protocol. Briefly, $1 \mu \mathrm{g}$ total RNA was labeled and hybridized with miRNA Complete Labeling and Hyb kit (Agilent Technologies, Inc.). Slides were then washed with Gene Expression Wash Buffer kit (Agilent Technologies, Inc.), and scanned by Agilent Microarray Scanner (Agilent Technologies, Inc.). The data were analyzed with Feature
Table I. Primer sequences of miRNAs used for reverse transcription-quantitative polymerase chain reaction.

\begin{tabular}{ll} 
Gene name & \multicolumn{1}{c}{ Forward primer sequence } \\
\hline hsa-miR-7641 & 5'-TTGATCTCGGAAGCTAAGC-3' \\
hsa-miR-4485-3p & 5'-TAACGGCCGCGGTACCCTAA-3' \\
hsa-miR-7-5p & 5'-TGGAAGACTAGTGATTTTGTT \\
& GTT-3' \\
hsa-miR-5703 & 5'-AGGAGAAGTCGGGAAGGT-3' \\
hsa-miR-630 & 5'-AGTATTCTGTACCAGGGAAG \\
& GT-3'
\end{tabular}

miR/miRNA, microRNA.

Extraction software (version 10.7; Agilent Technologies, Inc.) using the default settings.

Microarray analysis of $m R N A$ expression. For mRNA analysis, the array (OE BioTech) was performed using an Agilent expression profile gene chip (Agilent Technologies, Inc.). Two samples were allocated to the control and pressure groups. Total RNA was extracted using TRIzol ${ }^{\circledR}$ reagent (Thermo Fisher Scientific, Inc.) according to the manufacturer's protocol and quantified using NanoDrop 2000 (NanoDrop Technologies; Thermo Fisher Scientific, Inc.), and detected with an Agilent Bioanalyzer 2100 (Agilent Technologies, Inc.). The Quick Amp Labeling kit (One-Color; Agilent Technologies, Inc.) was used to reverse transcribe total RNA to double-stranded cDNA, prepare the label reaction and transcribe cRNAs from cDNAs, all according to the manufacturer's protocol. Subsequently, an RNeasy Mini kit (Qiagen $\mathrm{GmbH}$ ) was used to purify the labeled/amplified RNAs and quality control-labeled cRNAs. Each slide was hybridized with cyanine 3-labeled RNA using the Agilent Gene Expression Hybridization kit (Agilent Technologies, Inc.) in a Hybridization Oven (Thermo Fisher Scientific, Inc.) at $65^{\circ} \mathrm{C}$ for $17 \mathrm{~h}$. After hybridization, slides were washed in staining dishes with Gene Expression Wash Buffer kit (Agilent Technologies, Inc.). Slides were scanned using the Agilent Microarray Scanner (Agilent Technologies, Inc.) and analyzed using the Feature Extraction software (version 10.7; Agilent Technologies, Inc.) with default settings.

Reverse transcription-quantitative polymerase chain reaction (RT-qPCR). TRIzol ${ }^{\circledR}$ reagent (Thermo Fisher Scientific, Inc.) was used to extract RNA from cancer cells, according to the manufacturer's protocol. A NanoDrop 2000 spectrophotometer (NanoDrop Technologies; Thermo Fisher Scientific, Inc.) was used to measure RNA quantity and quality. Standard denaturing agarose gel electrophoresis was used to access RNA integrity (20). An Mir-X ${ }^{\mathrm{TM}}$ miRNA First Strand Synthesis kit (Clontech Laboratories, Inc.) was applied to reverse transcribe miRNA, and a PrimeScript ${ }^{\mathrm{TM}}$ RT Reagant kit (Takara Bio, Inc.) was applied to reverse transcribe mRNA. The reverse transcription reactions for miRNA and mRNA were conducted according to manufacturers' protocols. qPCR was performed on a Rotor Gene 3000 real-time PCR system from Corbett Research (Qiagen $\mathrm{GmbH}$ ). Mir-X ${ }^{\mathrm{TM}}$ miRNA RT-qPCR 
Table II. Primer sequences of mRNAs used for reverse transcription-quantitative PCR.

\begin{tabular}{lll}
\hline Gene name & \multicolumn{1}{c}{ Forward primer } & Reverse primer \\
\hline MMP1 & 5'-GTGTCTGGTCAATGGTTATCC-3' & 5'-GCCAGATTATTTCCGTGG-3' \\
MMP2 & 5'-CAGGACATTGTCTTTGATGGCATCGC-3' & 5'-TACCGTCAAAGGGGTATCCAT-3' \\
MMP7 & 5'-TCTCCTCCGAGACCTGTCC-3' & 5'-GCTGACATCATGATTGGCTTT-3' \\
MMP14 & 5'-GCCGGGGCATCCAGCAACTTTA-3' & 5'-TCCTCACCCGCCAGAACCAG-3' \\
TIMP1 & 5'-CAGAACCGCAGGGAGGAG-3' & 5'-CCCAGGGAACCAGGAAGG-3' \\
LAMA4 & 5'-GTGTAGGAATTGCTTACGCAACA-3' & 5'-GCTAACCGCAGGTCATCAGT-3' \\
SRC & 5'-GACAGGCTACATCCCCAGC-3' & 5'-CGTCTGGTGATCTTGCCAAAA-3' \\
ERBB3 & 5'-CGAGATTCTGTCAGGGGGTG-3' & 5'-ATCTCAGCATCTCGGTCCCT-3' \\
PIK3R1 & 5'-AGCATTGGGACCTCACATTACACA-3' & 5'-ACTGGAAACACAGTCCATGCACATA-3' \\
CTNNB1 & 5'-AGCTTCCAGACACGCTATCAT-3' & 5'-CGGTACAACGAGCTGTTTCTAC-3' \\
FAK & 5'-GCTTACCTTGACCCCAACTTG-3' & 5'-ACGTTCCATACCAGTACCCAG-3' \\
CLPTM1L & 5'-AGAAACAATGGGACGCTGTATG-3' & 5'-GCTTGGGGACCATGTAGGTG-3' \\
TP53I3 & 5'-AATGCTTTCACGGAGCAAATTC-3' & 5'-TTCGGTCACTGGGTAGATTCT-3' \\
FSCN1 & 5'-CTGCTACTTTGACATCGAGTGG-3' & 5'-GGGCGGTTGATGAGCTTCA-3' \\
GAPDH & 5'-CAATGACCCCTTCATTGACC-3' & 5'-GACAAGCTTCCCGTTCTCAG-3
\end{tabular}

MMP, matrix metalloproteinase; TIMP, tissue inhibitor of metalloproteinases; LAMA4, laminin subunit $\alpha$ 4; SRC, sarcoma gene; ERBB3, Erb-B2 receptor tyrosine kinase 3; PIK3R1, phosphoinositide 3-kinase regulatory subunit 1; CTNNB1, catenin $\beta$ 1; FAK, focal adhesion kinase; CLPTM1L, cleft lip and palate transmembrane protein 1-like protein; TP53I3, tumor protein P53 inducible protein 3; FSCN1, fascin actin-bundling protein.

SYBR $^{\circledR}$ kit (Takara Bio, Inc.) was used to amplify the cDNA of the detected miRNA. The reaction system had a total volume of $10 \mu \mathrm{l}$, consisting of $5 \mu \mathrm{l} \mathrm{SYBR}$ Advantage premix (2X), 3.6 $\mu \mathrm{l}$ double-distilled $\mathrm{H}_{2} \mathrm{O}, 0.2 \mu \mathrm{l}$ ROX Dye (50X), $0.2 \mu \mathrm{l}$ forward (F) primer, $0.2 \mu \mathrm{l}$ reverse $(\mathrm{R})$ primer and $0.8 \mu \mathrm{l}$ DNA sample. The thermocycling conditions were as follows: $95^{\circ} \mathrm{C}$, $10 \mathrm{sec}$, followed by 40 cycles at $95^{\circ} \mathrm{C}$ for $5 \mathrm{sec}$ and $60^{\circ} \mathrm{C}$ for 20 sec. TB Green ${ }^{\mathrm{TM}}$ Premix Ex Taq ${ }^{\mathrm{TM}}$ II kit (Takara Bio, Inc.) was used to amplify cDNA of the detected mRNA. The reaction system also comprised a $10-\mu 1$ total volume, consisting of $5 \mu \mathrm{l}$ TB Green Premix Ex Taq II (Tli RNaseH Plus; 2X), $0.4 \mu \mathrm{l} \mathrm{F}$ primer, $0.4 \mu \mathrm{l} \mathrm{R}$ primer, $0.2 \mu \mathrm{l}$ ROX Reference Dye (50X), $1 \mu \mathrm{l}$ DNA sample and $3 \mu$ l double-distilled $\mathrm{H}_{2} \mathrm{O}$. The thermocycling conditions were as follows: $95^{\circ} \mathrm{C}$ for $30 \mathrm{sec}$, followed by 40 cycles at $95^{\circ} \mathrm{C}$ for $5 \mathrm{sec}$ and $60^{\circ} \mathrm{C}$ for $30 \mathrm{sec}$. The primers (Wcgene Biotech) used in this study are listed in Tables I and II. The reverse primers for miRNA RT-qPCR were taken from the kit. GAPDH was used as an internal reference for mRNA expression detection, whereas U6 was used as an internal reference for miRNA expression detection. All tests were independent and repeated three times. miRNA and mRNA expression levels were calculated based on the $2^{-\Delta \Delta \mathrm{Cq}}$ method (21). The results were statistically analyzed and presented as the means \pm standard deviation (SD).

Bioinformatics analysis. Target genes of miRNAs were predicted from three databases, including miRDB V6.0 (www.mirdb.org), MiRTarBase (mirtarbase.mbc.nctu.edu. tw/php/index.php) and TargetScan V7.2 (www.targetscan. org/vert_72). All data were obtained from the databases in June 2018. The annotations were collected from the GO (geneontology.org) and the National Center for Biotechnology
Information (www.ncbi.nlm.nih.gov) databases. The Kyoto Encyclopedia of Genes and Genomes (KEGG) database was used for genome/metagenome annotation (www.genome. $\mathrm{jp} / \mathrm{kegg} /$ annotation). On the basis of the aforementioned analytical tools, specific biological processes and pathways were found to be enriched. $\mathrm{P}<0.05$ and false discovery rate $<0.25$ were used to define the threshold of significance. The miRNA-gene network was produced using Cytoscape 3.6 (22).

Statistical analysis. All data are expressed as the means \pm SD. A Student's t-test was used to analyze data from two groups. Data from three or more groups were analyzed using one-way ANOVA followed by least significant difference post hoc comparison test. $\mathrm{P} \leq 0.05$ was considered to indicate a statistically significant difference.

\section{Results}

Mechanical pressure regulates the proliferation of liver cancer cells. The proliferation of 2D-cultured liver cancer cell lines was determined using the CCK-8 assay (Fig. 1A and B). The results demonstrated that proliferation was increased under $15 \mathrm{mmHg}$ pressure for $24 \mathrm{~h}$ in the HepG2 $(\mathrm{P}<0.05)$ and Huh-7 $(\mathrm{P}<0.01)$ cell lines. Conversely, $60 \mathrm{mmHg}$ pressure for $48 \mathrm{~h}$ decreased proliferation of HepG2 $(\mathrm{P}<0.05)$ and Huh-7 $(\mathrm{P}<0.01)$ cell lines.

The liver cancer cell lines were also cultured in 3D Life Hydrogel (Fig. 1C) before being pressurized and were treated with Accutase enzymes prior to detection by flow cytometry (Fig. 1D). The results revealed that the ratio of cells in $\mathrm{S}$ phase was significantly increased in response to $15 \mathrm{mmHg}$ pressure for $24 \mathrm{~h}(\mathrm{P}<0.001$; Fig. $1 \mathrm{E}$ and $\mathrm{F})$. 

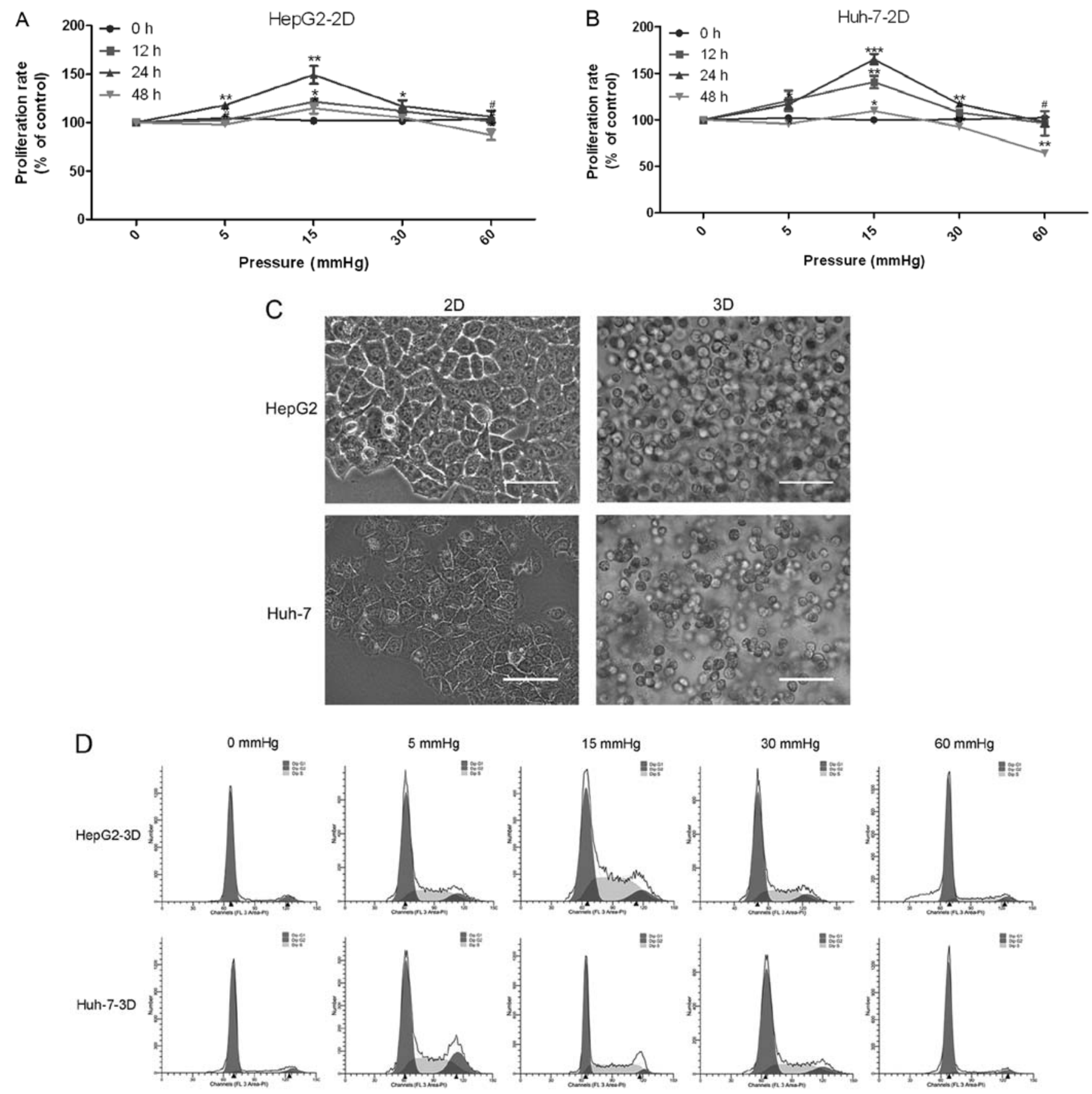

$\mathrm{E}$

HepG2-3D

$\mathrm{F}$

Huh-7-3D
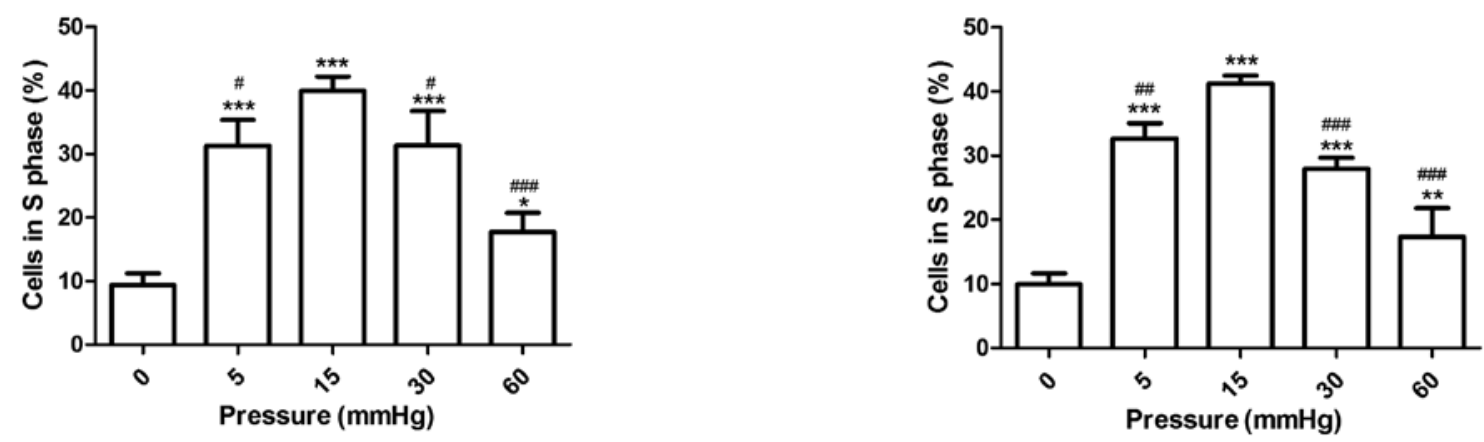

Figure 1. Effects of elevated pressure on the proliferation of HepG2 and Huh-7 liver cancer cells in vitro. 2D-cultured (A) HepG2 and (B) Huh-7 liver cancer cells were cultivated under pressure $(0,5,15,30$ and $60 \mathrm{mmHg})$ and observed at different time points $(0,12,24$ and 48 h); their proliferation (relative to the control group) was assessed using the Cell Counting kit-8 assay. (C) Morphology of 2D-cultured and 3D-cultured liver cancer cell lines (magnification, x400). Uneven illumination was corrected using a control image. Scale bar=50 $\mu \mathrm{m}$. (D) Flow cytometry results of 3D-cultured cells under pressure for $24 \mathrm{~h}$; the ratio of (E) HepG2 and (F) Huh-7 cells in the $\mathrm{S}$ phase of the cell cycle was evaluated using a cell cycle assay. 

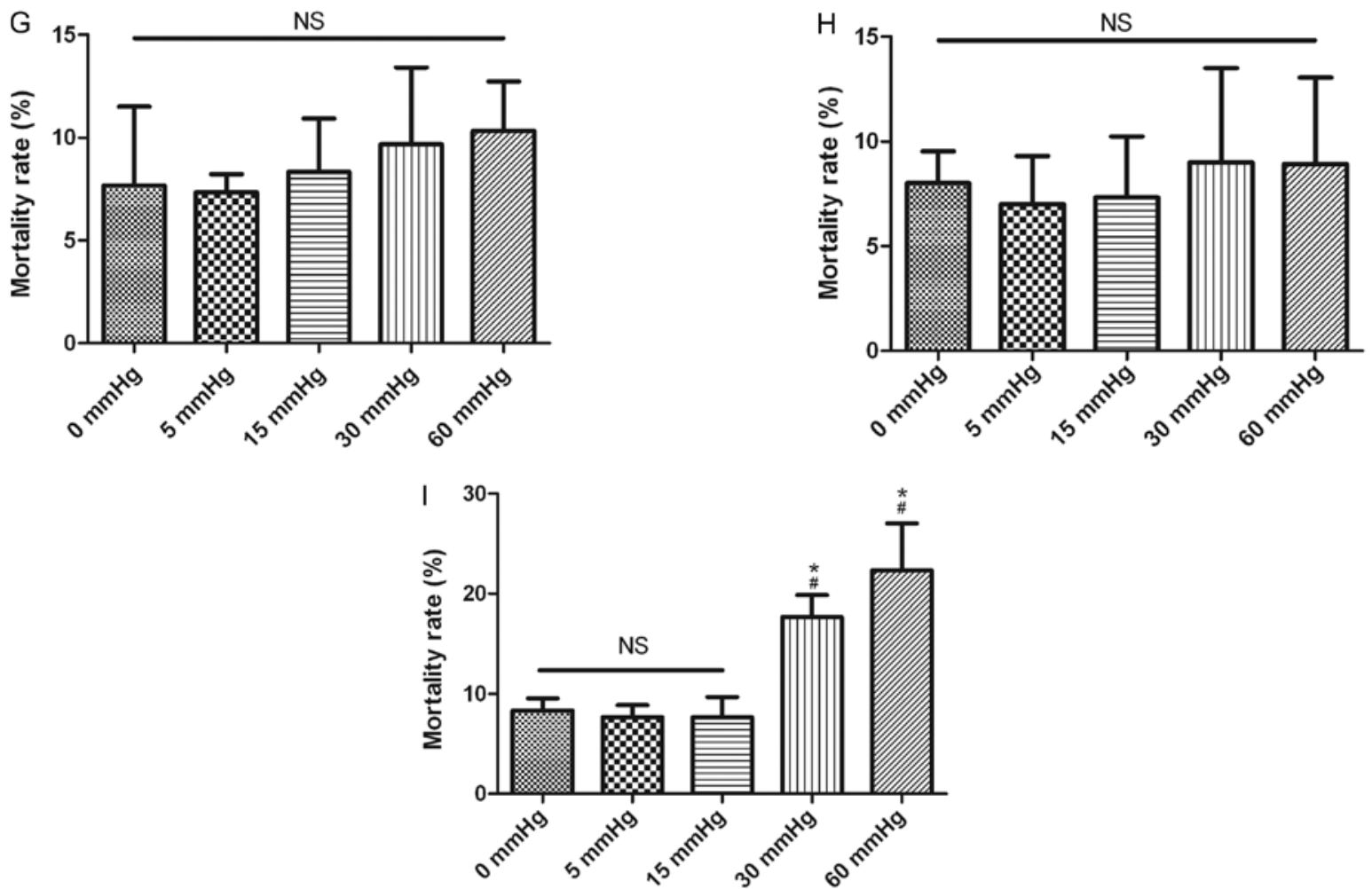

Figure 1. Continued. Effects of elevated pressure on the proliferation of HepG2 and Huh-7 liver cancer cells in vitro. Mortality rate for HepG2 pressurized at $15 \mathrm{mmHg}$ for (G) 12, (H) 24 and (I) $48 \mathrm{~h}$. All data are expressed as the means \pm standard deviation. The data were analyzed using ANOVA, followed by the least significant difference post hoc test. ${ }^{*} \mathrm{P}<0.05,{ }^{* *} \mathrm{P}<0.01$ and ${ }^{* * *} \mathrm{P}<0.001$ vs. $0 \mathrm{mmHg} .{ }^{\#} \mathrm{P}<0.05,{ }^{\# \#} \mathrm{P}<0.01$ and ${ }^{\# \# \#} \mathrm{P}<0.001$ vs. $15 \mathrm{mmHg}$. 2D, 2-dimensional; 3D, 3-dimensional; NS, not significant.

Mechanical pressure regulates the invasion of liver cancer cells. The migration and invasion of 2D-cultured liver cancer cell lines were examined using a wound-healing assay (Fig. 2A-D) and Transwell assay (Fig. 2E-G), respectively. The results demonstrated that the percentage of invasive and migratory cells was increased under $15 \mathrm{mmHg}$ pressure for $24 \mathrm{~h}(\mathrm{P}<0.001)$, with no statistical difference between the $0 \mathrm{mmHg}$ group and the $60 \mathrm{mmHg}$ group.

RT-qPCR was used to detect the expression of tumor metastasis-related genes in 3D-cultured liver cancer cells. Matrix metalloproteinases (MMPs) can degrade components of the ECM to induce tumor metastasis; MMPs are in turn inhibited by tissue inhibitors of metalloproteinases (TIMPs) (23). Therefore, the expression levels of MMP1, MMP2, MMP7 and MMP14, which represent collagenase, gelatinase, matrix degrading enzyme and membrane-type MMP, respectively, and TIMP1, which can inhibit almost all subtypes of MMPs, were evaluated. In HepG2 and Huh-7 cell lines, the expression levels of MMP1, MMP7 and MMP14 in the cells pressurized at $15 \mathrm{mmHg}$ for $24 \mathrm{~h}$ were significantly higher compared with in the other groups, whereas TIMP1 expression exhibited the opposite trend. In addition, MMP2 was increased in cells pressurized at $15 \mathrm{mmHg}$ for $24 \mathrm{~h}$ compared with in the control group ( $\mathrm{P}<0.01$; Fig. $2 \mathrm{H}$ and $\mathrm{I})$.

Mechanical pressure regulates the mortality of liver cancer cells. For 2D-cultured liver cancer cells, trypan blue staining was used to determine the cell death rate under various pressures. The results indicated that there was no significant difference in the mortality rate between cells under different pressures for 12 and $24 \mathrm{~h}$ (Fig. 1G and H). Conversely, the mortality rate was increased after $48 \mathrm{~h}$ of 30 and $60 \mathrm{mmHg}$ compression $(\mathrm{P}<0.05$; Fig. 1I).

Identification and integrative analysis of miRNAs and $m R N A s$. The HepG2 cell line was pressurized at $15 \mathrm{mmHg}$ for $24 \mathrm{~h}$, and mRNA and miRNA expression was evaluated via microarray analysis. Five miRNAs were identified using the miRNA chip (fold change $\geq 1.2, \mathrm{P} \leq 0.05$; Fig. $3 \mathrm{~A}$ ). miR-7-5p, miR-7641 and miR-4485-3p were upregulated, whereas miR-5703 and miR-630 were downregulated under pressure (Table III). In addition, 10,150 mRNAs were differentially expressed according to mRNA chip analysis (fold change $\geq 2$, $\mathrm{P} \leq 0.05$; Fig. 3B). A total of 5,102 genes were upregulated, including oncogenes such as sarcoma gene (SRC), focal adhesion kinase (FAK), phosphoinositide 3-kinase (PI3K) regulatory subunit 1 (PIK3R1), integrin subunit $\alpha \mathrm{V}$ (ITGAV), son of sevenless 1 (SOS1), insulin receptor substrate 1 (IRS1) and serum/glucocorticoid regulated kinase 3 (SGK3). 5,048 genes were downregulated, including tumor suppressor genes such as SMAD family member 2 (SMAD2), casein kinase $1 \varepsilon$ (CSNK1E) and forkhead box O 1 (FOXO1).

The expression of laminin subunit $\alpha 4$, SRC, Erb-B2 receptor tyrosine kinase 3, PIK3R1, catenin $\beta 1$, FAK, cleft lip and palate transmembrane protein 1-like protein, tumor protein P53 inducible protein 3, fascin actin-bundling protein 1 and all five miRNAs was evaluated by RT-qPCR in the HepG2 and Huh-7 cell lines, which were treated under 2D and 3D pressure-loading conditions. The results revealed a similar trend to the microarray analyses, confirming the changes 
A

HepG2-2D
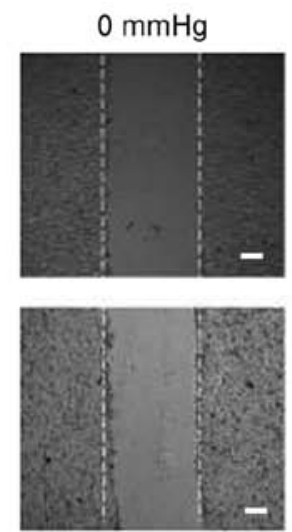

B

$0 \mathrm{mmHg}$

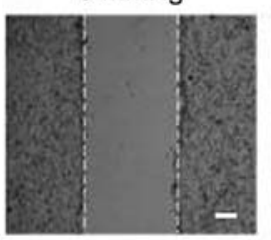

Huh-7-2D

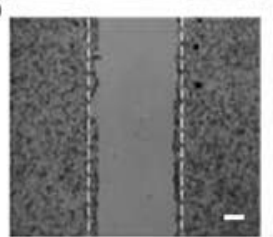

C

HepG2-2D

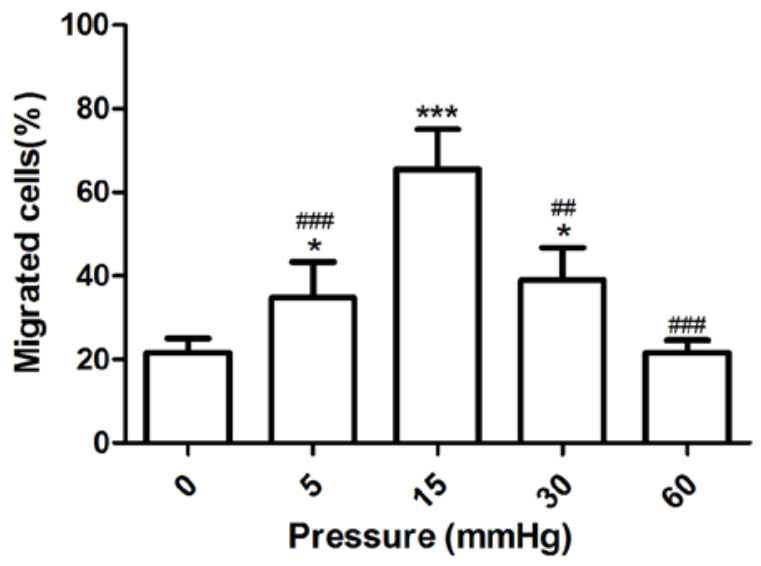

E

$0 \mathrm{mmHg}$

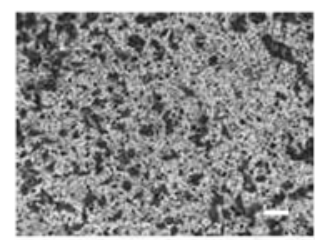

HepG2-2D
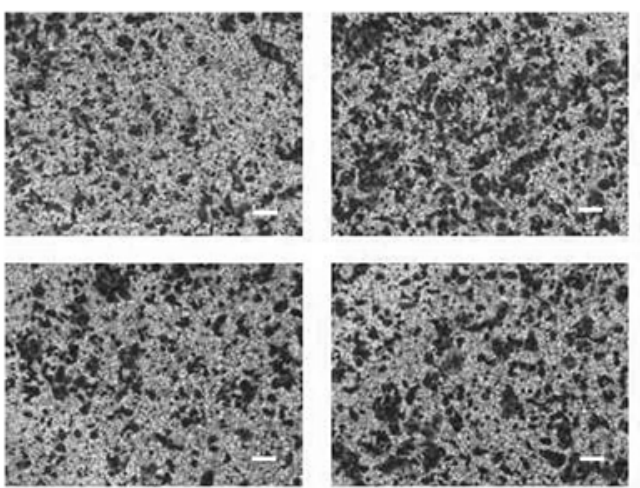

$5 \mathrm{mmHg}$
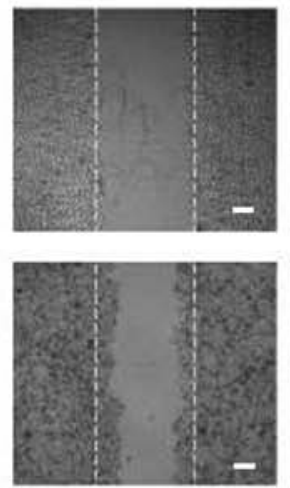

$5 \mathrm{mmHg}$
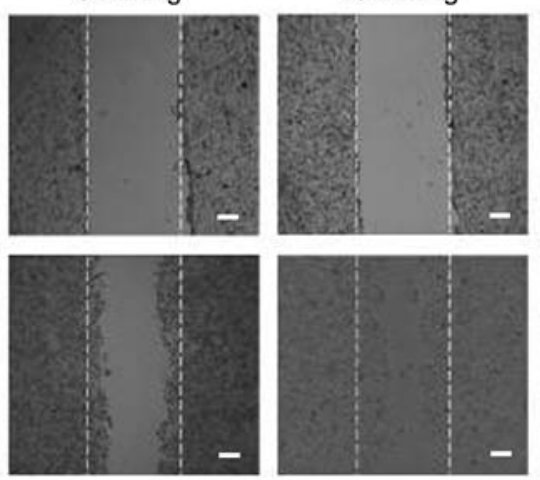

D

$15 \mathrm{mmHg}$

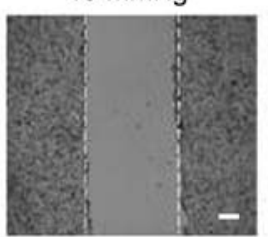

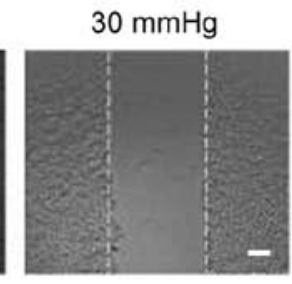
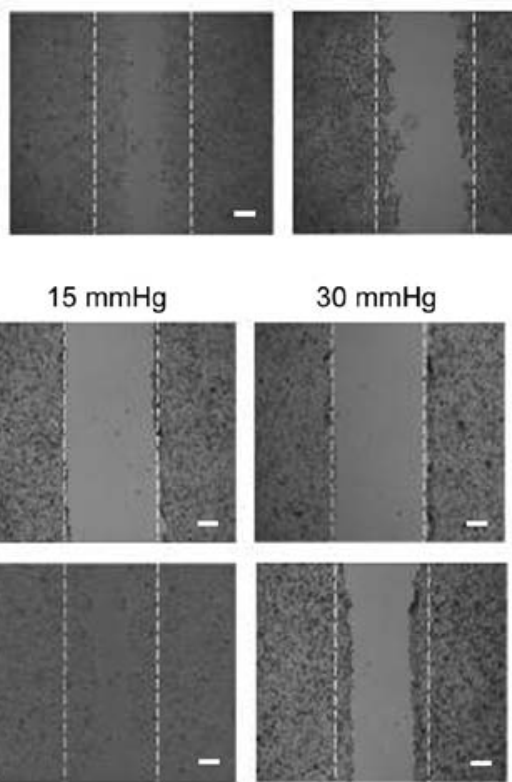

Huh-7-2D
$60 \mathrm{mmHg}$
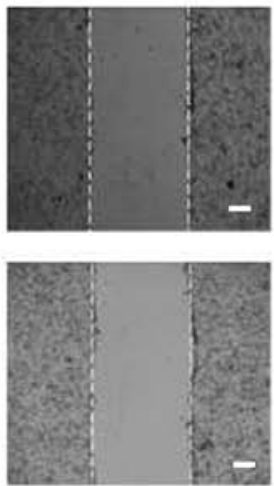

$60 \mathrm{mmHg}$
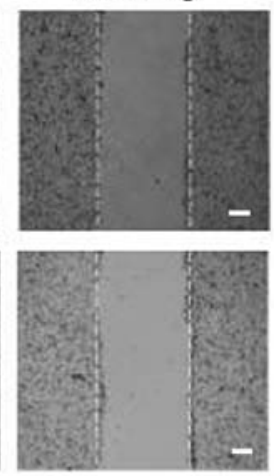

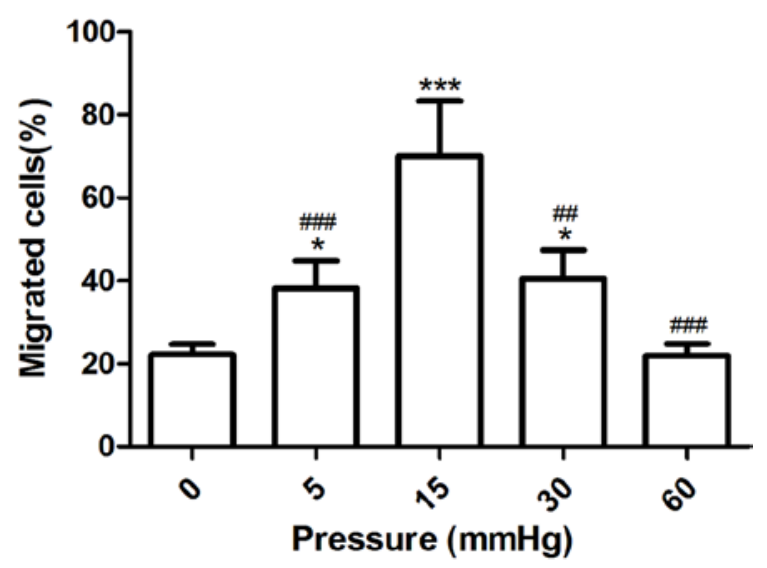

$15 \mathrm{mmHg}$

$30 \mathrm{mmHg}$

$60 \mathrm{mmHg}$
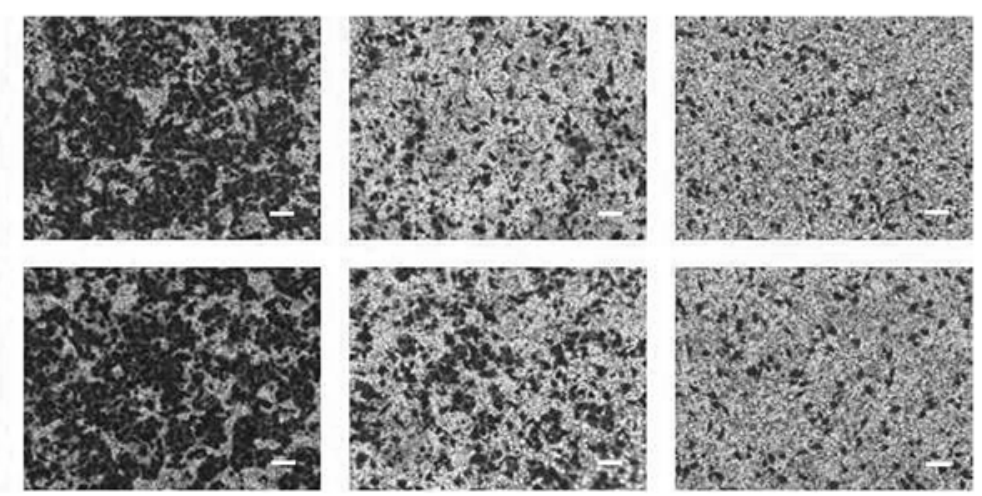

Figure 2. Effect of pressure on HepG2 and Huh-7 liver cancer cell migration and invasion in vitro. (A) HepG2 and (B) Huh-7 confluent cell monolayers were wounded and cultured under different levels of pressure $(0,5,15,30,60 \mathrm{mmHg}$ ) for $24 \mathrm{~h}$ (magnification, x 100); (C) HepG2 and (D) Huh-7 percentage of migration was calculated. (E) Representative images of Transwell assay results showing cells stained with $0.1 \%$ crystal violet solution (magnification, $\mathrm{x} 100$ ). 
$\mathrm{F}$

HepG2-2D

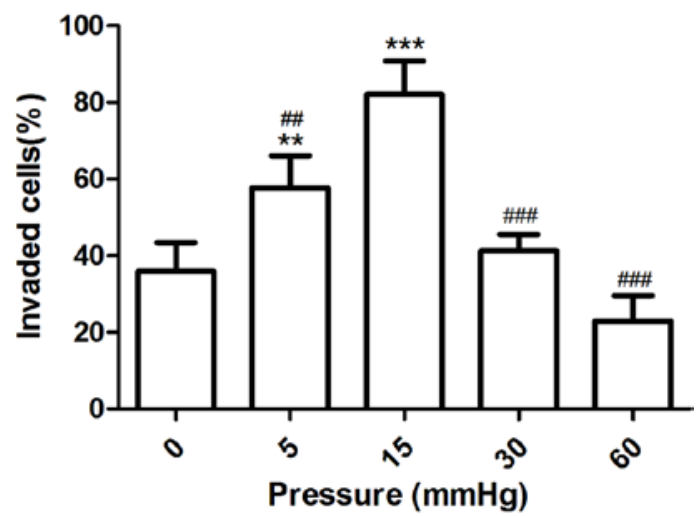

$\mathrm{H}$
G

Huh-7-2D

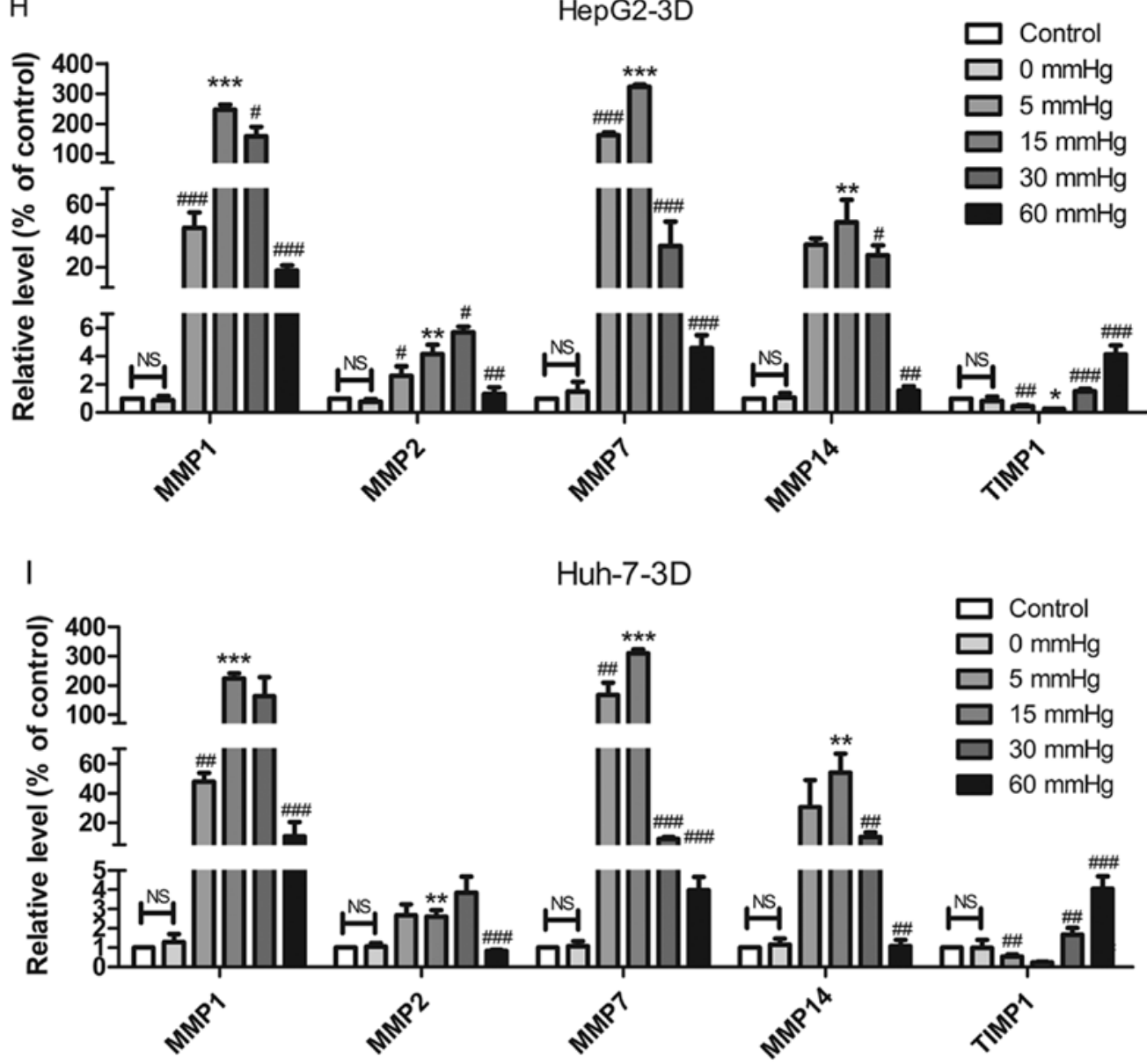

Figure 2. Continued. Effect of pressure on HepG2 and Huh-7 liver cancer cell migration and invasion in vitro. The assay lasted 24 h, and after fixing and staining, the percentage of $(\mathrm{F})$ HepG2 and $(\mathrm{G})$ Huh-7 cells on the lower chamber was calculated; $10 \%$ acetic acid was used to elute the stained inserts to detect the percentage of invaded cells. mRNA expression levels of MMP1, MMP2, MMP7, MMP14 and TIMP1 in 3D-cultured (H) HepG2 and (I) Huh-7 cells exposed to different levels of pressure $(0,5,15,30,60 \mathrm{mmHg})$ for $24 \mathrm{~h}$. All data are expressed as the means \pm standard deviation. The data were analyzed using ANOVA, followed by the least significant difference post hoc test. ${ }^{*} \mathrm{P}<0.05,{ }^{* *} \mathrm{P}<0.01$ and ${ }^{* * *} \mathrm{P}<0.001 \mathrm{vs} .0 \mathrm{mmHg}$. ${ }^{\#} \mathrm{P}<0.05$, ${ }^{\# \#} \mathrm{P}<0.01$ and ${ }^{\# \# \#} \mathrm{P}<0.001 \mathrm{vs}$. $15 \mathrm{mmHg}$. 2D, 2-dimensional; 3D, 3-dimensional; MMP, matrix metalloproteinase; TIMP, tissue inhibitor of metalloproteinases; NS, not significant.

detected in the expression levels of mRNAs and miRNAs (Fig. 3C-J).

Three online databases were used to predict the target genes of the five pressure-responsive miRNAs, and the sum aggregate of the predictive target genes was integrated with the differentially expressed mRNAs from the mRNA chip. With this approach, a total of 1,309 genes (642 downregulated,

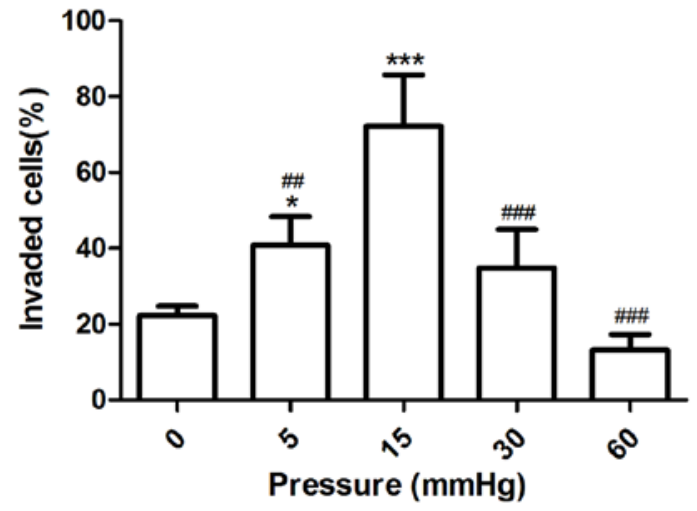

HepG2-3D

uh-7-3D 

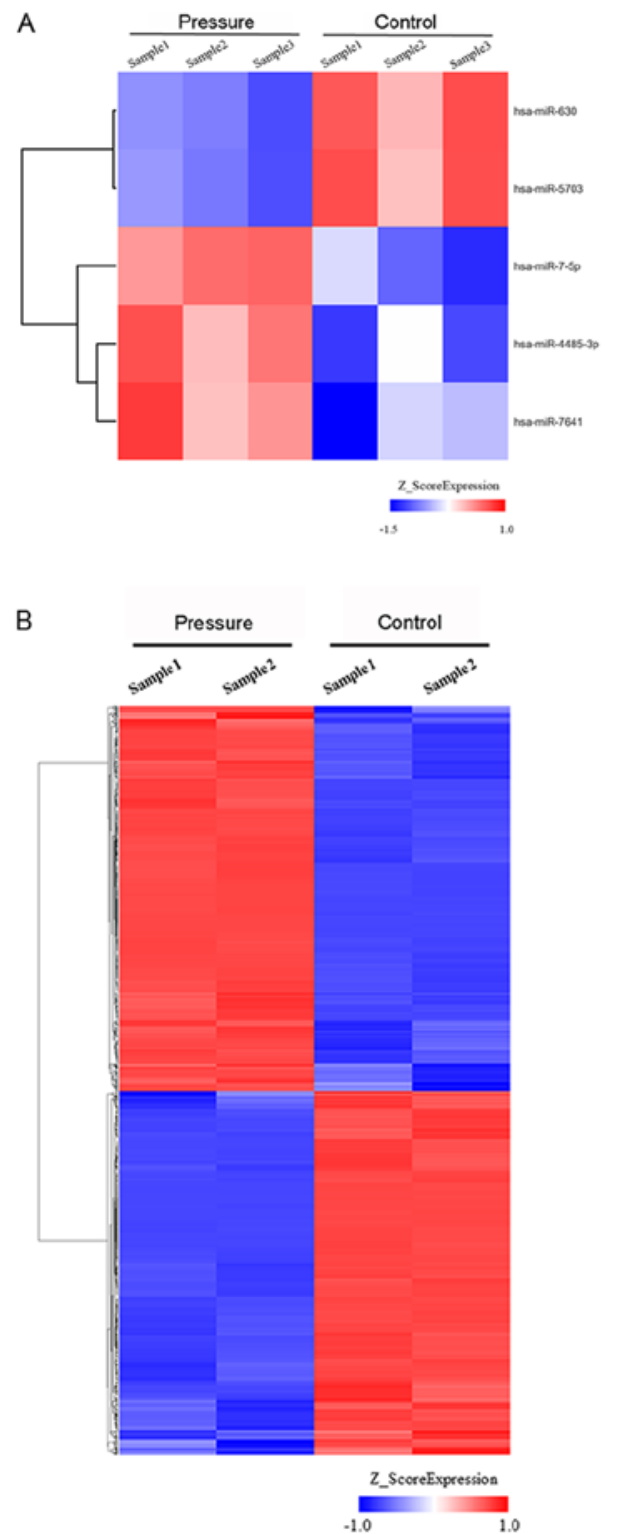

C

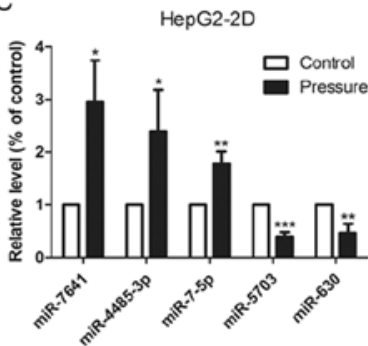

E

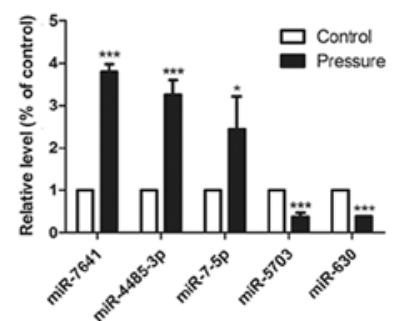

D

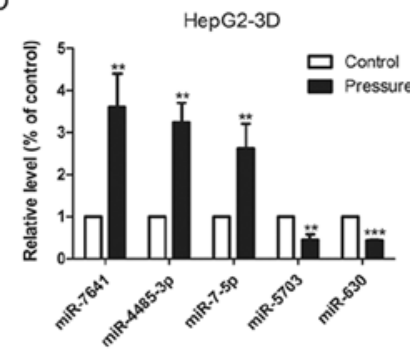

F

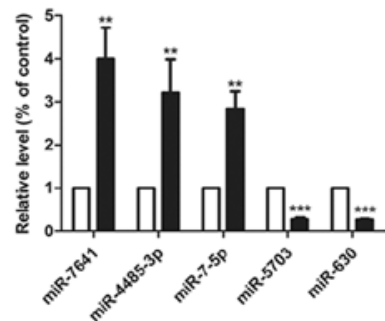

H
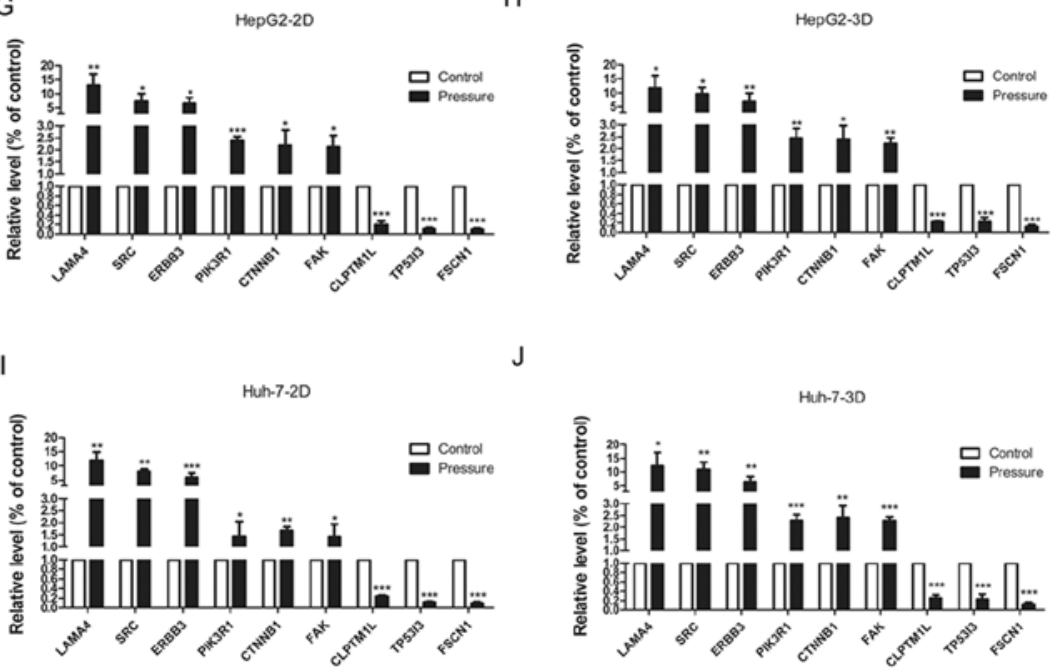

G
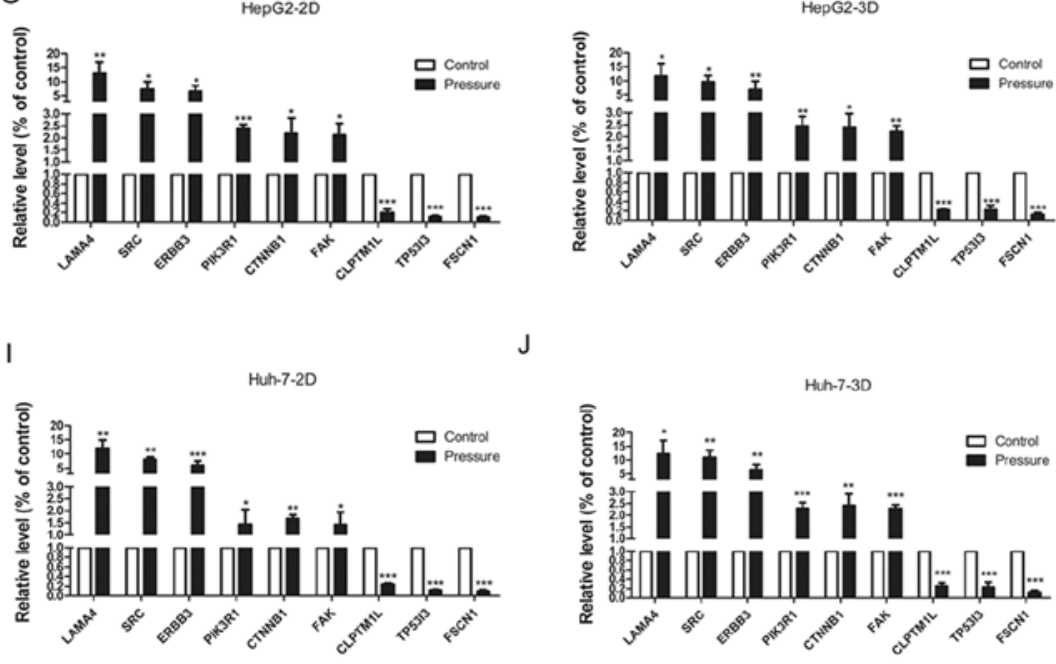

Figure 3. Differently expressed miRNAs and mRNAs in cells treated with $15 \mathrm{mmHg}$ for $24 \mathrm{~h}$, as determined by microarray analysis and RT-qPCR. (A) In the cluster heat map, changes in miRNA expression (fold change $\geq 1.2, \mathrm{P} \leq 0.05$ ) in HepG2 cells were illustrated, and three pressure-upregulated miRNAs and two pressure-downregulated miRNAs were identified. (B) In the cluster heat map, changes in mRNA expression (fold change $\geq 2, \mathrm{P} \leq 0.05$ ) in HepG2 cells are illustrated. A total of 5,102 pressure-activated mRNAs and 5,048 pressure-repressed mRNAs were identified. Quantitative analysis of the transcript levels (relative to the control) of five miRNAs identified by miRNA chip of HepG2 cells cultured in (C) 2D and (D) 3D and Huh-7 cells cultured in (E) 2D and (F) 3D The expression levels of nine genes identified by mRNA chip in HepG2 cells, cultured in (G) 2D and (H) 3D, and Huh-7 cells, also cultured in (I) 2D and (J) 3D, were evaluated via RT-qPCR. All data are expressed as the means \pm standard deviation, and analyzed using Student's t-test. ${ }^{*} \mathrm{P}<0.05,{ }^{* * *} \mathrm{P}<0.01$ and ${ }^{* * * *} \mathrm{P}<0.001$. 2D, 2-dimensional; 3D, 3-dimensional; miRNA, microRNA; RT-qPCR, reverse transcription-quantitative polymerase chain reaction.

'integrin-mediated signaling pathway' and 'cell migration'. The top three cancer development-associated terms identified by pathway analysis were 'PI3K-Akt signaling pathway', 'Focal adhesion' and 'FoxO signaling pathway'.

\section{Discussion}

In the present study, the effects of elevated pressure on $\mathrm{HepG} 2$ and Huh-7 cells cultured in 2D and 3D conditions were evaluated, and it was observed that a pressure of $15 \mathrm{mmHg}$ for $24 \mathrm{~h}$ increased the proliferation, migration and invasion of liver cancer cells. Notably, the proliferation of 2D-cultured liver cancer cells under 30 and $60 \mathrm{mmHg}$ compression for $48 \mathrm{~h}$ was decreased compared with that at $0 \mathrm{mmHg}$, suggesting that there is an optimal pressure range that favors liver cancer cell proliferation. Excessive pressure or its prolonged application may constitute unfavorable conditions for liver cancer cell survival, and only under moderate pressure and exposure time $(15 \mathrm{mmHg}, 24 \mathrm{~h})$ can these cells thrive. For 3D-cultured liver cancer cells, the number of cells in $\mathrm{S}$ phase following $24 \mathrm{~h}$ of $60 \mathrm{mmHg}$ compression was higher than that of cells grown with no compression. It is therefore possible that the encapsulation of liver cancer cells in a 3D matrix may protect them from damage caused by higher pressures, and/or attenuate the pressure-induced inhibition of DNA synthesis.

The wound-healing assay showed that, compared with in the control group, the percentage of migratory cells was significantly increased under 15 or $30 \mathrm{mmHg}$ pressure for 
Table III. Differentially expressed miRNAs in pressure-stimulated cells compared with control cells.

A, Downregulated microRNAs

\begin{tabular}{llr}
\hline Systematic name & P-value & Fold-change \\
\hline hsa-miR-630 & 0.004232634 & 0.679781 \\
hsa-miR-5703 & 0.006772327 & 0.727266 \\
\hline
\end{tabular}

B, Upregulated microRNAs

\begin{tabular}{llr}
\hline Systematic name & P-value & Fold-change \\
\hline hsa-miR-7641 & 0.047364561 & 1.517495 \\
hsa-miR-7-5p & 0.025880795 & 1.291842 \\
hsa-miR-4485-3p & 0.041582116 & 1.234361 \\
\hline
\end{tabular}

$\mathrm{miR} / \mathrm{miRNA}$, microRNA.

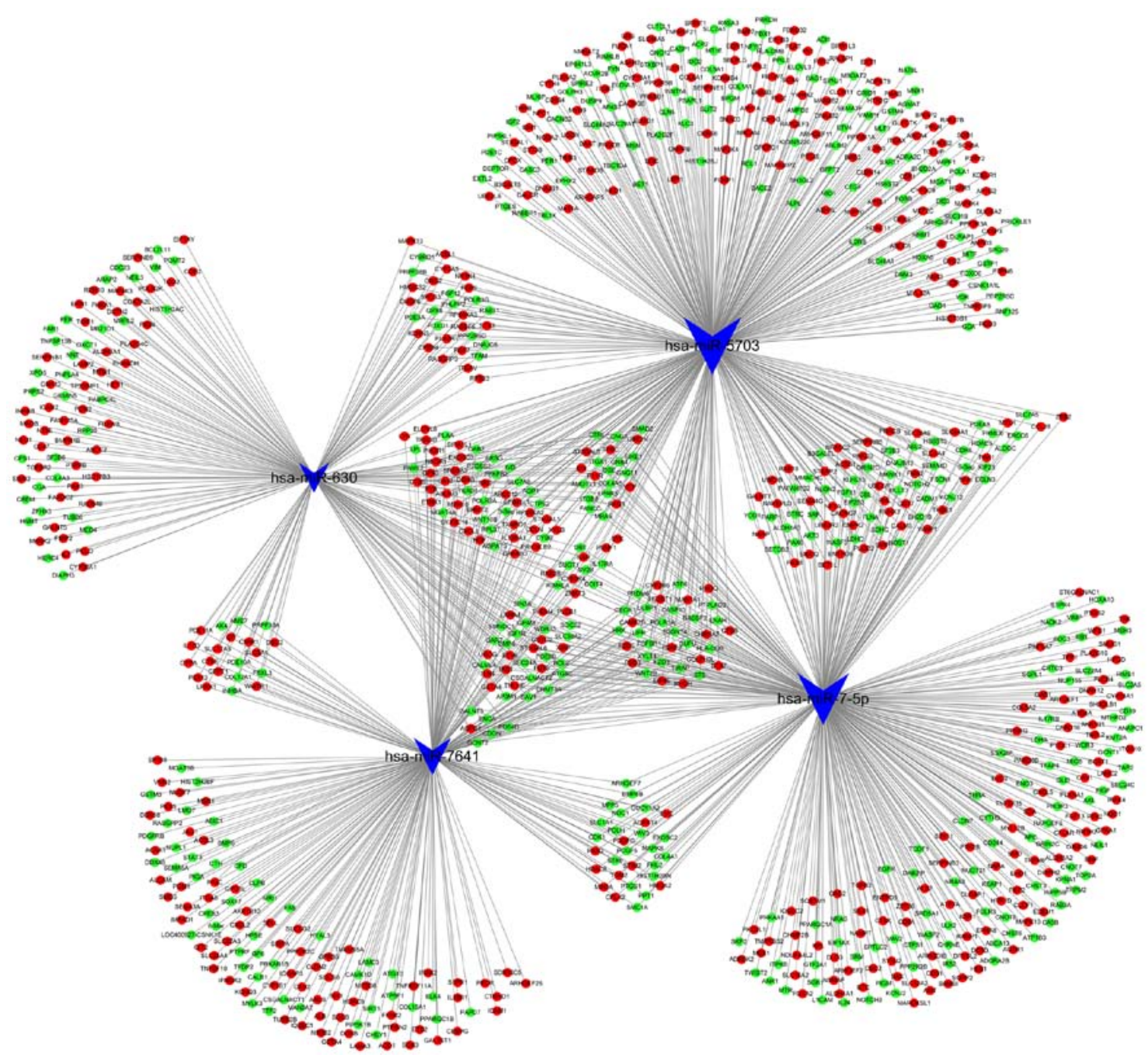

Figure 4. miRNA-gene network. According to the interactions between miRNAs and the 1,309 integrated target genes, a miRNA-gene network was generated. The blue arrowheads represent differentially expressed miRNAs; the red circles represent upregulated mRNAs; and the green circles represent downregulated mRNAs. miRNA, microRNA.

$24 \mathrm{~h}$, whereas $60 \mathrm{mmHg}$ pressure did not affect cell migration. This indicated that pressure may promote the migratory ability of liver cancer cells at appropriate conditions $(15 \mathrm{mmHg}$ for 24 h). Notably, the levels of cell mortality were unchanged 
A

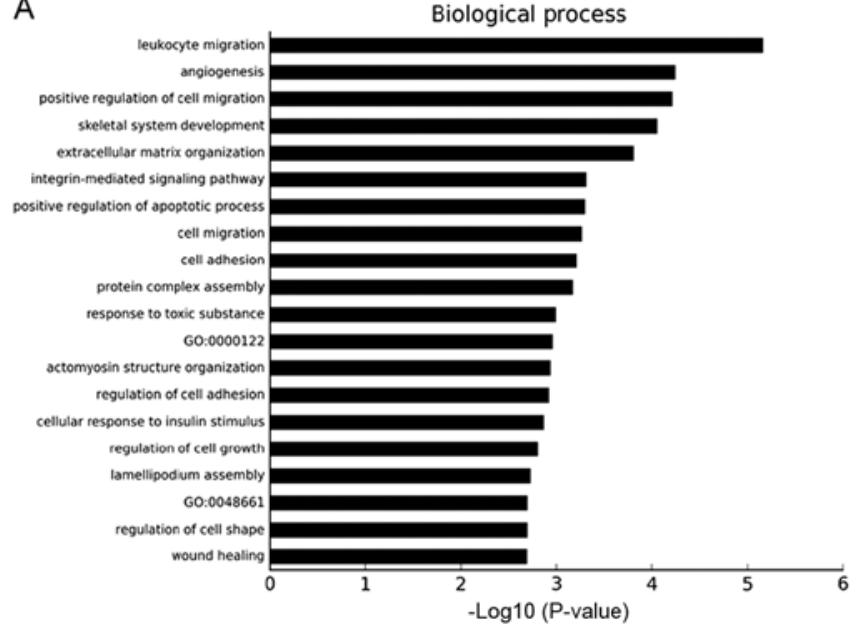

B

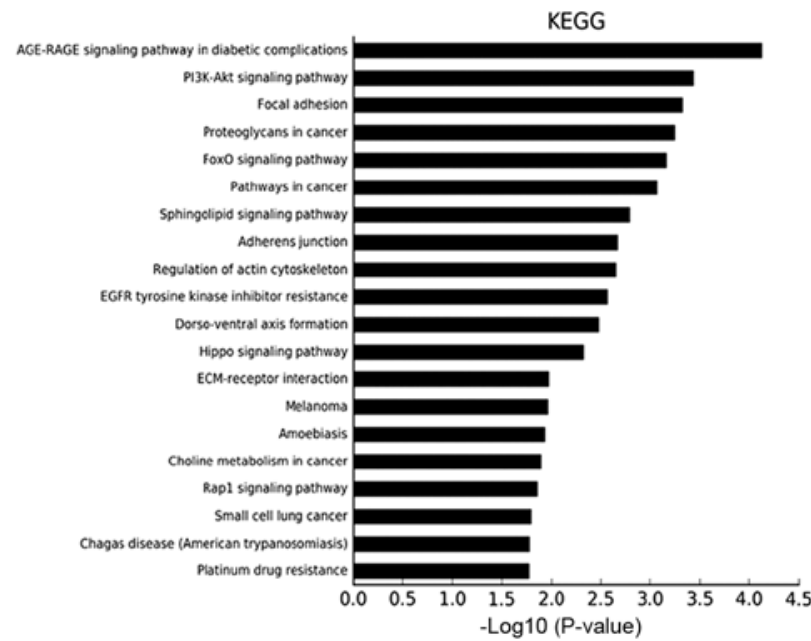

Figure 5. GO and KEGG bioinformatics analyses. (A) Top 20 GO terms enriched in the integrated 1,309 mRNAs. (B) Top 20 KEGG pathways enriched in the integrated 1,309 mRNAs. GO, Gene Ontology; KEGG, Kyoto Encyclopedia of Genes and Genomes.

under elevated pressure for 12 and $24 \mathrm{~h}$, but were increased following compression for $48 \mathrm{~h}$. As trypan blue can only stain cells with membrane defects, and the membranes of cells undergoing apoptosis may be undamaged (24), it is therefore possible that high pressure (30 and $60 \mathrm{mmHg}$ ) may also induce liver cancer cell apoptosis, which may reduce the number of living cells able to migrate during the wound-healing assay. Furthermore, it is possible that excessive pressure may activate the expression of migration-suppressing genes. The mechanisms underlying the mechanically induced changes in cell migration require further study.

Under the optimal conditions identified using the aforementioned tests $(15 \mathrm{mmHg}, 24 \mathrm{~h})$, the microarray analysis identified five miRNAs that exhibited differences in expression; these differences were also detected by RT-qPCR. Alterations in the mRNA expression profile were more complex, which suggests that the effect of pressure on liver cancer cells may affect various physiological processes, including endocytosis, apoptosis and metabolism. Following integrative analysis of miRNAs and mRNAs, the 1,309 target genes were functionally evaluated using GO analysis, and these were mostly associated with cell proliferation and migration.

In the KEGG pathway analysis of the 1,309 differentially expressed mRNAs, 'PI3K/Akt signaling pathway' and 'focal adhesion' were second and third of the top 20 most enriched annotations, while the 'integrin-mediated signaling pathway' ranked sixth in GO analysis annotations. There are several interactions between these pathways that may explain the migration and invasion of malignant cells $(25,26)$. The expression levels of the key genes of these three pathways, including SRC, FAK, PI3K and ITGAV, were all significantly upregulated after $15 \mathrm{mmHg}$ compression for $24 \mathrm{~h}$. Src and ITGAV were the predicted target genes of downregulated miR-5703 and miR-630, respectively. Previous biomechanical studies have confirmed that Src, FAK, PI3K and ITGAV are vital proteins involved in cell mechanical stress transduction. Thamilselvan and Basson (4) reported that extracellular pressure may increase integrin affinity and promote colon cancer adhesion via actin-dependent inside-out FAK and Src signals, which may regulate metastatic tumor cell adhesion (27). In a separate study, it was reported that the Src inhibitor PP2 could inhibit the phosphorylation of PI3K and protein kinase B (Akt) in pressure models of colon cancer, and that the application of LY294002 (a PI3K inhibitor) inhibited the pressure-mediated adhesion process of colon cancer cells. Accordingly, the Src-PI3K-FAK-Akt signaling axis may respond to pressure in colon cancer cells (28). In addition, extracellular pressures reaching $29 \mathrm{mmHg}$ have been reported in rapidly growing breast cancers (29). Downey et al (30) observed breast cancer cells under $15 \mathrm{mmHg}$ and demonstrated that cancer cells display increased adhesion, stimulated by phosphorylated (p)-FAK, which is the same as for colon cancer. Genes that were responsive to pressure in the pressure models of colon cancer and breast cancer may also function in the pressure model of liver cancer. They may act as target genes of pressure-responsive microRNAs, regulating the proliferation, migration and invasion of pressure-treated liver cancer cells. The phosphorylation of FAK, Src and PI3K may serve an important role in regulating other downstream pathways, including the FOXO signaling pathway, which ranked fifth in pathway analysis annotations. PI3K can phosphorylate SGKs by activating pyruvate dehydrogenase kinase 1 , and SGKs then deactivate FOXOs. Furthermore, p-FOXOs have been reported to inhibit the expression of p27kip and p21, which prevent cell cycle arrest and apoptosis (31). SOS1 (32) and IRS1 (33), which are upstream of FOXOs, may be targeted by miRNA-630 and upregulated in pressure-exposed liver cancer cells according to the microarray. SOS1 can activate Ras (34), thereby phosphorylating downstream genes and inhibiting the expression of FOXO. IRS1 may act as an oncogene, as it has been reported to be involved in tumor initiation and progression by regulating PI3K (35). Therefore, the FOXO signaling pathway may be downregulated by a reduction in SRC expression induced by mechanically responsive miR-5703, or by a reduction in ITGAV, SOS1 and IRS1 expression via pressure-induced upregulation of miR-630.

In addition to the downregulated miR-630 and miR-5703, upregulated miR-7641 and miR-7-5p may also be associated with the development of liver cancer in a high-pressure 
tumor microenvironment. Downregulation of CSNK1E and SMAD2 was observed in liver cancer cells exposed to $15 \mathrm{mmHg}$ pressure for $24 \mathrm{~h}$ according to the microarray analysis. CSNK1E is a predictive target gene of miR-7-5p, and higher CSNK1E levels are associated with a better prognosis in subsets of patients with breast cancer (36). SMAD2 is a putative target gene of miRNA-7641, and as an intracellular mediator of the transforming growth factor $\beta$ signal transduction pathway, it may have a relevant role in hepatic fibro-carcinogenesis (37).

In summary, it was hypothesized that pressure signals may act on cell membranes to deform them, which may lead to activation of proteins on the surface of cell membranes, which then transfer pressure stimulation to the cytoskeleton, organelles and distal cell membranes. The activation of pressure-sensitive cell membrane surface proteins may induce the tyrosine-mediated phosphorylation of cytoskeletal proteins, including paxillin and vinculin, and may trigger the upregulation or downregulation of other signaling factors (such as PI3K, FAK, IRS1, SOS1, FOXOs, CSNK1E and SMAD2). This process may therefore occur in liver cancer cells under pressure, and mechanically responsive miRNAs may be recruited to regulate the proliferation, migration and invasion of liver cancer cells. Other miRNAs and mRNAs screened using microarray analyses were identified in the present study, and these will be evaluated in future studies regarding the function of pressure in liver cancer.

HSCs are the primary producer of liver ECM components. It has been reported that metastatic colorectal cancer stem cells in the liver are capable of initiating the formation of a metastatic niche by reprogramming HSCs into CAFs (38). A previous study also revealed that pressure interventions at $10 \mathrm{mmHg}$ for $1 \mathrm{~h}$ may significantly enhance the proliferation, activation and migration of HSCs via miR-9a-5p, which targets Sirt1 (13). Regarding the effects of pressure and mechanically responsive miRNAs, further experiments consisting of liver cancer cells, HSCs and CAFs, in combination or separately, should be designed to broaden our knowledge of liver cancer evolution and malignancy.

In conclusion, to the best of our knowledge, no previous studies have demonstrated the effects of mechanical pressure on liver cancer. The present study reported that pressure induced an aggressive cancer phenotype, promoting proliferation and migration of liver cancer cells. Potential pressure-responsive miRNAs and mRNAs were identified by gene chips, which may provide a large number of potential therapeutic targets for clinical treatments, and revealed how intrahepatic pressure may promote cancer development. However, the effect of these specific pressure-responsive miRNAs and their targets should be verified in further in vitro and in vivo experiments, and the molecular mechanism underlying pressure-induced proliferation and migration of liver cancer cells requires further study. Answering these questions may be of significance for the treatment of liver cancer with portal hypertension and may help reduce the levels of intraoperative mechanical stimulation-induced metastasis of liver cancer. Overall, the present study aimed to understand the fate of liver cancer cells following mechanically induced miRNA expression, and may provide a strong theoretical basis for the prevention and treatment of liver cancer.

\section{Acknowledgements}

Not applicable.

\section{Funding}

The present study was supported by the National Natural Science Foundation of China (grant no. 11472300).

\section{Availability of data and materials}

The datasets generated and/or analyzed during the current study are available in the Gene Expression Omnibus repository, www.ncbi.nlm.nih.gov/geo/query/acc.cgi?acc= GSE119881 and www.ncbi.nlm.nih.gov/geo/query/acc.cgi? acc $=$ GSE120194. The datasets used and/or analyzed during the current study are available from the corresponding author on reasonable request.

\section{Authors' contributions}

SS proposed the study. SS and XL performed the research and wrote the first draft. SS, KWG and YCS collected and analyzed the data. All authors contributed to the design and interpretation of the study and to further drafts. LZ and DKY were the guarantors, and made substantial contributions to conception and design of the study, and the interpretation of data. LZ and DKY revised the contents of the manuscript prior to submission, and were responsible for all aspects of the research work.

\section{Ethics approval and consent to participate}

Not applicable.

\section{Patient consent for publication}

Not applicable.

\section{Competing interests}

The authors declare that they have no competing interests.

\section{Author information}

LZ is a Professor in the Second Affiliated Hospital of the Second Military Medical University, a member of the Shanghai Biomechanics Professional Committee and a peer-reviewed expert of the National Natural Science Foundation of China (NSFC). His main research direction is the biomechanical study of digestive system diseases and tumors, with emphasis on liver hemodynamics and gastrointestinal dynamics. For many years, his team has studied the hemodynamics of portal hypertension before and after TIPS (Transjugular intrahepatic portosystemic shunt), and completed the NSFC project entitled: 'The role and mechanism of microRNAs in the biomechanical response of hepatic stellate cells'. The research reported by this manuscript is part of another NSFC project entitled: 'The role of microRNAs regulating the differentiation and invasion of hepatoma in response to mechanical force'. 


\section{References}

1. Omata M, Cheng AL, Kokudo N, Kudo M, Lee JM, Jia J, Tateishi R, Han KH, Chawla YK, Shiina S, et al: Asia-Pacific clinical practice guidelines on the management of hepatocellular carcinoma: A 2017 update. Hepatol Int 11: 317-370, 2017.

2. Kalli M and Stylianopoulos T: Defining the role of solid stress and matrix stiffness in cancer cell proliferation and metastasis. Front Oncol 8: 55, 2018.

3. Jain RK, Martin JD and Stylianopoulos T: The role of mechanical forces in tumor growth and therapy. Annu Rev Biomed Eng 16 321-346, 2014

4. Thamilselvan V and Basson MD: Pressure activates colon cancer cell adhesion by inside-out focal adhesion complex and actin cytoskeletal signaling. Gastroenterology 126: 8-18, 2004.

5. Craig DH, Owen CR, Conway WC, Walsh MF, Downey $\mathrm{C}$ and Basson MD: Colchicine inhibits pressure-induced tumor cell implantation within surgical wounds and enhances tumor-free survival in mice. J Clin Invest 118: 3170-3180, 2008.

6. Basson MD, Zeng B, Downey C, Sirivelu MP and Tepe JJ: Increased extracellular pressure stimulates tumor proliferation by a mechanosensitive calcium channel and PKC- $\beta$. Mol Oncol 9: 513-526, 2015

7. Fiering S, Ang LH, Lacoste J, Smith TD and Griner E; Reproducibility Project: Cancer Biology: Registered report: Biomechanical remodeling of the microenvironment by stromal caveolin-1 favors tumor invasion and metastasis. Elife 4: e04796, 2015.

8. Fernández-Sánchez ME, Barbier S, Whitehead J, Béalle G, Michel A, Latorre-Ossa H, Rey C, Fouassier L, Claperon A, Brullé L, et al: Mechanical induction of the tumorigenic $\beta$-catenin pathway by tumour growth pressure. Nature 523: 92-95, 2015.

9. Ambros V: microRNAs: Tiny regulators with great potential. Cell 107: 823-826, 2001.

10. Zhou J, Li YS, Nguyen P, Wang KC, Weiss A, Kuo YC, Chiu JJ, Shyy JY and Chien S: Regulation of vascular smooth muscle cell turnover by endothelial cell-secreted microRNA-126: Role of shear stress. Circ Res 113: 40-51, 2013.

11. Zhou J, Wang KC, Wu W, Subramaniam S, Shyy JY, Chiu JJ, Li JY and Chien S: MicroRNA-21 targets peroxisome proliferators-activated receptor-alpha in an autoregulatory loop to modulate flow-induced endothelial inflammation. Proc Nat Acad Sci USA 108: 10355-10360, 2011.

12. Wang KC, Garmire LX, Young A, Nguyen P, Trinh A, Subramaniam S, Wang N, Shyy JY, Li YS and Chien S: Role of microRNA-23b in flow-regulation of Rb phosphorylation and endothelial cell growth. Proc Natl Acad Sci USA 107: 3234-3239, 2010.

13. Qi F, Hu JF, Liu BH, Wu CQ, Yu HY, Yao DK and Zhu L: MiR-9a-5p regulates proliferation and migration of hepatic stellate cells under pressure through inhibition of Sirt1. World J Gastroenterol 21: 9900-9915, 2015.

14. Seitz HK and Stickel F: Risk factors and mechanisms of hepatocarcinogenesis with special emphasis on alcohol and oxidative stress. Biol Chem 387: 349-360, 2006.

15. Fattovich G, Stroffolini T, Zagni I and Donato F: Hepatocellular carcinoma in cirrhosis: Incidence and risk factors. Gastroenterology 127 (5 Suppl 1): S35-S50, 2004.

16. Iwakiri Y: Pathophysiology of portal hypertension. Clin Liver Dis 18: 281-291, 2014.

17. Perelló A, Escorsell A, Bru C, Gilabert R, Moitinho E, García-Pagán JC and Bosch J: Wedged hepatic venous pressure adequately reflects portal pressure in hepatitis $\mathrm{C}$ virus-related cirrhosis. Hepatology 30: 1393-1397, 1999.

18. Okada Y, Tsuzuki Y, Hokari R, Miyazaki J, Matsuzaki K, Mataki N, Komoto S, Watanabe C, Kawaguchi A, Nagao S, et al: Pressure loading and ethanol exposure differentially modulate rat hepatic stellate cell activation. J Cell Physiol 215: 472-480, 2008.

19. Asaumi H, Watanabe S, Taguchi M, Tashiro M and Otsuki M: Externally applied pressure activates pancreatic stellate cells through the generation of intracellular reactive oxygen species. Am J Physiol Gastrointest Liver Physiol 293: G972-G978, 2007.
20. Fleige S and Pfaffl MW: RNA integrity and the effect on the real-time qRT-PCR performance. Mol Aspects Med 27: 126-139, 2006.

21. Livak KJ and Schmittgen TD: Analysis of relative gene expression data using real-time quantitative PCR and the 2(-Delta Delta C(T)) Method. Methods 25: 402-408, 2001.

22. Shannon P, Markiel A, Ozier O, Baliga NS, Wang JT, Ramage D, Amin N, Schwikowski B and Ideker T: Cytoscape: A software environment for integrated models of biomolecular interaction networks. Genome Res 13: 2498-2504, 2003.

23. Nagase H, Visse R and Murphy G: Structure and function of matrix metalloproteinases and TIMPs. Cardiovasc Res 69: $562-573,2006$

24. Martini M, De Santis MC, Braccini L, Gulluni F and Hirsch E: PI3K/AKT signaling pathway and cancer: An updated review. Ann Med 46: 372-383, 2014.

25. Kerr JF, Wyllie AH and Currie AR: Apoptosis: A basic biological phenomenon with wide-ranging implications in tissue kinetics. Br J Cancer 26: 239-257, 1972

26. Guan X: Cancer metastases: Challenges and opportunities. Acta Pharm Sin B 5: 402-418, 2015.

27. Kavic SM and Basson MD: Environmental factors of temperature, humidity, serum accumulation and cell seeding increase colon cancer cell adhesion in vitro, with partial characterization of the serum component responsible for pressure-stimulated. J Surg Res 98: 89-96, 2001.

28. Thamilselvan V, Craig DH and Basson MD: FAK association with multiple signal proteins mediates pressure-induced colon cancer cell adhesion via a Src-dependent PI3KAkt pathway. FASEB J 21: 1730-1741, 2007.

29. Nathanson SD and Nelson L: Interstitial fluid pressure in breast cancer, benign breast conditions and breast parenchyma. Ann Surg Oncol 1: 333-338, 1994.

30. Downey C, Alwan K, Thamilselvan V, Zhang L, Jiang Y, Rishi AK and Basson MD: Pressure stimulates breast cancer cell adhesion independently of cell cycle and apoptosis regulatory protein (CARP)-1 regulation of focal adhesion kinase. Am J Surg 192: 631-635, 2006.

31. Nakamura Y, Hibino K, Yanagida T and Sako Y: Switching of the positive feedback for RAS activation by a concerted function of SOS membrane association domains. Biophys Physicobiol 13: 1-11, 2016.

32. Li P, Tang T, Liu T, Zhou J, Cui H, He Z, Zhong Y, Hu E, Yang A, Wei G, et al: Systematic Analysis of tRNA-Derived Small RNAs reveals novel potential therapeutic targets of traditional Chinese medicine (Buyang-Huanwu-Decoction) on intracerebral hemorrhage. Int J Biol Sci 15: 895-908, 2019.

33. Papatheodorou I, Petrovs R and Thornton JM: Comparison of the mammalian insulin signalling pathway to invertebrates in the context of FOXO-mediated ageing. Bioinformatics 30: 2999-3003, 2014

34. Wu X, Cui CL, Chen WL, Fu ZY, Cui XY and Gong X: miR-144 suppresses the growth and metastasis of laryngeal squamous cell carcinoma by targeting IRS1. Am J Transl Res 8: 1-11, 2016.

35. Coomans de Brachène A and Demoulin JB: FOXO transcription factors in cancer development and therapy. Cell Mol Life Sci 73: 1159-1172, 2016

36. Lopez-Guerra JL, Verdugo-Sivianes EM, Otero-Albiol D, Vieites B, Ortiz-Gordillo MJ, De León JM, Praena-Fernandez JM, Marin JJ and Carnero A: High CSNK1E levels are correlated with better prognosis in subsets of patients with breast cancer. Oncotarget 6: 30343-30356, 2015.

37. Yoshida K, Murata M, Yamaguchi $T$ and Matsuzaki K: TGF- $\beta /$ Smad signaling during hepatic fibro-carcinogenesis (review). Int J Oncol 45: 1363-1371, 2014.

38. Tauriello DV, Calon A, Lonardo E and Batlle E: Determinants of metastatic competency in colorectal cancer. Mol Oncol 11: 97-119, 2017

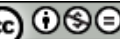

This work is licensed under a Creative Commons Attribution-NonCommercial-NoDerivatives 4.0 International (CC BY-NC-ND 4.0) License. 